\title{
Heart Rate Variability as an Index of Cue Reactivity in Alcoholics
}

\author{
I. Rajan, P.J. Naga Venkatesha Murthy, A.G. Ramakrishnan, B.N. Gangadhar, and \\ N. Janakiramaiah
}

Background: Autonomic responses follow exposure to conditioned stimuli such as contextual factors associated with alcohol ingestion. Heart rate variability is under autonomic control and may be a measure of such response.

Methods: Twenty alcoholics and 23 matched social drinkers (all male) were exposed to a neutral cue and then an alcohol cue in identical settings, during which the electrocardiogram of these subjects was recorded. Time and frequency domain parameters of heart rate variability (HRV) were computed by a blind rater.

Results: Coefficient of variation of $R-R$ intervals and absolute powers of $H R V$ spectrum (in frequency bands $0.05-0.15 \mathrm{~Hz}$ and $0.01-0.05 \mathrm{~Hz}$ ) following alcohol cue were significantly higher in alcoholics than social drinkers. The mean heart rate (MHR) failed to reflect this difference.

Conclusions: HRV paradigm appears more sensitive than MHR to measure cue reactivity. Biol Psychiatry 1998; 43:544-546 (C) 1998 Society of Biological Psychiatry

Key Words: Heart rate variability, alcohol dependence, cue reactivity

\section{Introduction}

A conditioning analysis of drug dependence presumes that the drugs with abuse potential act as reinforcing stimuli. Contextual factors associated with drug ingestion also can acquire conditioning properties through repeated pairing. These stimuli and their mental representations can elicit autonomic arousal by associative learning processes (Childress et al 1993; O’Brien et al 1992). Such conditioned arousal manifests as physiological responses to the drug cues. Alcoholics exhibit greater cue-reactivity to sight and smell of alcoholic beverage than nonaddicted

\footnotetext{
From the Department of Psychiatry, National Institute of Mental Health and Neurosciences, Bangalore, India (IR, PJNVM, BNG, NJ); and Department of Electrical Engineering, Indian Institute of Science, Bangalore, India (AGR). Address reprint requests to Dr. N. Janakiramaiah, MD, PhD. Additional Professor. Department of Psychiatry, National Institute of Mental Health and Neuro suiences, Bangalore-560 029, India.

Received April 29, 1997; revised July 8, 1997; accepted August 4. 1997.
}

control group on physiological parameters such as skin conductance, salivation, heart rate, and peripheral hypothermic response (Drummond et al 1990).

Spectral analysis of heart rate variability (HRV) is a recent noninvasive method of assessing cardiac autonomic tone (Malliani et al 1991; Castiglioni 1995). Sympathetic and parasympathetic nervous activity is shown to make frequency-specific contributions to the HRV power spectrum. Two major components, the high-frequency (HF) and low-frequency (LF) components of the HRV power spectrum, seem to reflect parasympathetic and sympathetic activities, respectively (Murata et al 1994). These sensitive indices of autonomic nervous system functioning could be used to measure autonomic perturbations in cue-conditioned response. In this study we explored the use of this measure to examine cue-conditioned response in alcoholics and social drinkers.

\section{Methods and Materials}

\section{Alcoholics}

Twenty inpatients (mean age $\pm \mathrm{SD}=33.75 \pm 6.3$ years) with alcohol dependence (ICD-10, World Health Organization 1992) of at least 2 years duration, with uncomplicated withdrawal state, were recruited after detoxification (14 days).

\section{Controls}

Twenty-three controls were age-matched (mean age $\pm \mathrm{SD}=$ $33.17 \pm 6.4$ years) male social drinkers with consumption not more than $50 \mathrm{~mL}$ of absolute alcohol equivalents per week, without any dependence features and whose last drink was prior to 1 week. The two groups had comparable years of age, education, and age at first drink. Family history of alcohol abuse was present in 13 cases of the alcohol group and 9 cases of social drinkers.

Subjects in both groups gave informed consent, and did not have any other psychiatric illness, other substance abuse (except smoking tobacco), or medical illness. All medications except vitamins were avoided for 48 hours, and a 4-hour smoking-free period was ensured before recording 
Table 1. Comparison of HRV Parameters between Social Drinkers and Alcoholics during Cue Exposure

\begin{tabular}{|c|c|c|c|c|c|c|}
\hline \multirow[b]{2}{*}{ HRV parameter } & \multicolumn{3}{|c|}{ Neutral cue } & \multicolumn{3}{|c|}{ Alcohol cue } \\
\hline & $\begin{array}{l}\text { Social drinkers } \\
\quad(n=23)\end{array}$ & $\begin{array}{l}\text { Alcoholics } \\
(n=20)\end{array}$ & $t(p)$ & $\begin{array}{l}\text { Social drinkers } \\
\quad(n=23)\end{array}$ & $\begin{array}{c}\text { Alcoholics } \\
(n=20)\end{array}$ & $t(p)$ \\
\hline MHR & $86.4(13.2)$ & $80.1(12.6)$ & $-1.59(0.12)$ & $87.6(13.4)$ & $84.1(11.8)$ & $-.91(.369)$ \\
\hline CVR & $4.8(2.2)$ & $5.4(2.6)$ & $0.77(0.44)$ & $5.5(2.5)$ & $8(3.5)$ & $3.22(.002)^{x}$ \\
\hline VLF & $3154.5(3629.5)$ & $4036.6(3012.7)$ & $0.86(0.39)$ & $4968.8(4232.5)$ & $9279.3(6327.5)$ & $2.66(.011)^{6}$ \\
\hline LF & $1919.7(1996.4)$ & $2078.3(1368.1)$ & $0.38(0.77)$ & $3295.1(3247.2)$ & $5908.1(4545.9)$ & $2.19(.034)^{\prime}$ \\
\hline $\mathrm{HF}$ & $763(729)$ & $1483(1734)$ & $1.8(0.07)$ & $1136.5(1138.4)$ & $1881.8(1691.7)$ & $1.71(.094)$ \\
\hline
\end{tabular}

MHR, mean heart rate in beats per minute: CVR, the coefficient of variation of R-R intervals (ratio of the standard deviation of the R-R intervals to the mean); VLF, the absolute power in the very low-frequency band $0.01-0.05 \mathrm{~Hz}$ (in beats $/ \mathrm{min}^{2} / \mathrm{Hz}$ ); LF, power in the low-frequency band $0.05-0 \mathrm{l} 15 \mathrm{~Hz}$. (in beats/min $/ \mathrm{Hz}$ ); $\mathrm{HF}$, powel in the high-frequency band $0.15-0.5 \mathrm{~Hz}$. (in beats $/ \mathrm{min}^{2} / \mathrm{Hz}$ ).

"Statistically significant.

\section{Procedure}

Recording was done in sitting posture, after acclimatization, in a sound-attenuated room between 17:00 and 20:00 hours, using a commercial electrocardiograph (ECG) monitor. ECG electrodes were applied to the left shoulder, right shoulder, and ninth left intercostal space. A glass of fruit juice (neutral cue) and rum (alcohol cue) were presented in that order but with an interval of $4 \mathrm{~min}$. Subjects were allowed to hold the glass and smell the content but not drink it. ECG was recorded for $4 \mathrm{~min}$ commencing at $30 \mathrm{sec}$ after each exposure. ECG signal was digitized $(500 \mathrm{~Hz})$, coded, and stored in a personal computer. Analysis was done by a rater blind to the experiment.

\section{HRV Analysis}

TIME DOMAIN ANALYSIS. The $R$ waves were detected after checking for artifacts and from the resulting $R-R$ interva] series, the mean heart rate (MHR), and the coefficient of variation of $R-R$ intervals (CVR-ratio of the standard deviation of the $R-R$ intervals to the mean) were computed.

FREQUENCY DOMAIN ANALYSIS. The instantaneous heart rate time series was obtained from the $R-R$ intervals. Linear interpolation (Kamath et al 1987) was applied on the HR time series to obtain heart rate samples evenly spaced at $0.25 \mathrm{sec}$. From this interpolated time series the mean was removed, and then using fast fourier transform technique, the power spectrum was obtained. The absolute power in the very low-frequency band (VLF, 0.01-0.05 Hz), the low-frequency band (LF, 0.05$0.15 \mathrm{~Hz}$ ), and the high-frequency band (HF, 0.15-0.5 Hz) were estimated. SPSS Release 6 was used for the analysis of the computed parameters. Two-tailed independent samples $t$ test was used for between-group comparisons. The level of significance was chosen at $p<.05$.

\section{Results}

With neutral cue exposure, no significant difference was noted between the two groups. In contrast, alcoholics had significantly larger HRV measures (CVR, VLF, LF) than social drinkers when exposed to alcohol cue (Table 1). Mean heart rate did not differentiate the two groups.

\section{Discussion}

Several precautions were taken to minimize the effects of known confounding factors. Situational anxiety response to new recording environment was minimized by acclimatization. First exposure was always to neutral cue in both groups, to avoid false attribution of situational autonomic arousal as response to alcohol cue. Data analysis by a blind rater eliminated observer bias. Since none reported any brand specificity of alcoholic beverage, and all had used and enjoyed rum, it was used uniformly as alcohol cue.

In our study, neutral cue exposure did not differentiate the alcoholics from social drinkers on any of the variables, but significant meaningful differences were apparent under alcohol cue exposure. Gross measures such as mean heart rate, frequently used in cue-reactivity research (Glautier and Drummond 1994), failed to reflect this difference. Autonomic arousal in response to alcohol cue was revealed by HRV parameters. Increase in CVR while responding to alcohol cue is indicative of the higher magnitude of short-term fluctuations of their cardiac interbeat interval. In the frequency domain measures of HRV, the power on the low-frequency band $(0.05-0.15 \mathrm{~Hz})$ reflects sympathetic activity and that of the high-frequency band $(0.15-0.5)$ reflects parasympathetic activity (Murata et al 1994). The finding of elevated spectral power on the low-frequency band in this study suggests increased sympathetic response to alcohol cue in alcoholics. We could not find any report in literature to date of a similar study to which to compare our results.

This study suggests that HRV measures are more sensitive than mean heart rate in assessing the cue reactivity. The merits of frequency domain measures 
relatives to the computationally simpler time domain measures (CVR) in quantifying cue response require further study. Future studies may also explore the usefulness of HRV parameters to predict relapse in detoxified alcoholics and to evaluate the efficacy of treatment modalities based on deconditioning principles.

\section{References}

Castiglioni P (1995): Evaluation of heart rhythm variability by heart rate or heart period: Differences, pitfalls and help from logarithms. Med Biol Eng Comput 33:323-330.

Childress AR, Hole AV, Ehrman RN, Robbins SJ, McLellan AT, O'Brien CP (1993): Cue reactivity and cue reactivity interventions in drug dependence. NIDA Res Monogr 137:73-95.

Drummond DC, Cooper T, Glautier S (1990): Conditioned learning in alcohol dependence: Implications for cue exposure treatment. Br $J$ Addict 85:725-743.
Glautier S, Drummond DC (1994): Alcohol dependence and cue reactivity. J Stud Alcohol 55:224-229.

Kamath MV, Ghista DN, Fallen EL, Fitchett D, Miller D, McKelvie R (1987): Heart rate variability power spectrogram as a potential non-invasive signature of cardiac regulatory system response, mechanisms, and disorders. Heart Vessels 3:33-41.

Malliani A, Pagani M, Lombardi F, Cerutti S (1991): Cardiovascular neural regulation explored in the frequency domain. Circulation 84:482-492.

Murata K, Araki S, Yokoyama K, Sata F, Yamashita K, Oyo Y (1994): Autonomic neurotoxicity of alcohol assessed by heart rate variability. J Auton Nerv Syst 48:105-111.

O'Brien CP, Childress AR, McLellan AT, Ehrman R (1992): A learning model of addiction. In: $\mathrm{O}$ 'Brien $\mathrm{CP}$, Jaffe $\mathrm{JH}$, editors. Addictive states. New York: Raven Press, pp 157 177.

World Health Organization (1992): International Classification of Diseases-10, Classification of Mental and Behavioral Disorders. Geneva: WHO. 